\title{
De dependentes da Estaco a dependentes do Estado: Desemprego de meia-idade e o Estado social como último reduto
}

From Estaco Dependents to State Dependents: Middle-aged: Unemployment and the Social State as a Last Bulwark Des dépendants d'Estaco aux dépendants de l'État : chômage au niveau d'âge moyen et l'État social comme ultime rempart

\section{Pedro Araújo}

\section{OpenEdition}

\section{Journals}

Edição electrónica

URL: http://journals.openedition.org/rccs/758

DOI: $10.4000 /$ rccs. 758

ISSN: 2182-7435

\section{Editora}

Centro de Estudos Sociais da Universidade de Coimbra

Edição impressa

Data de publição: 1 Outubro 2007

Paginação: 95-118

ISSN: 0254-1106

\section{Refêrencia eletrónica}

Pedro Araújo, « De dependentes da Estaco a dependentes do Estado: Desemprego de meia-idade e o Estado social como último reduto ", Revista Crítica de Ciências Sociais [Online], 78| 2007, colocado online no dia 01 outubro 2012, criado a 01 maio 2019. URL : http://journals.openedition.org/rccs/758 ; DOI : $10.4000 /$ rccs.758 


\section{De dependentes da Estaco a dependentes do Estado: Desemprego de meia-idade e o Estado social como último reduto'}

Traçam-se as grandes linhas de um modelo de análise das experiências do desemprego, prestando-se particular atenção a um dos seus pilares: os mediadores de compensação. No âmbito dos mediadores de compensação, analisa-se a função que o Estado social desempenha na organização de estratégias de adaptação à privação de emprego por parte dos desempregados de uma cerâmica de Coimbra, a Estaco, que encerrou em 2001. A posição central que desempenha o Estado social permite que se perspective o desemprego de meia-idade como um acontecimento que compromete a capacidade dos indivíduos para assegurar a sua autonomia financeira e que amplifica a função social do Estado.

Por vezes, uma ausência é capaz de deixar um eco muito próprio.

JEFF VANDERMEER (2006)

\section{Introdução}

Vinte e cinco de Outubro de 2005. O local é Coimbra, a zona industrial da Pedrulha. A situação: um plenário de ex-trabalhadores das Cerâmicas Estaco, Estatuária Artística, SA. Quatro anos passaram sobre a falência da Estaco. O suficiente para a fábrica se tornar irreconhecível. A maquinaria foi removida, as instalações esvaziadas e vandalizadas. Da Estaco resta apenas uma carcaça de cimento e ferro. De qualquer modo, não são festivas as razões que levaram à organização do plenário. Um grupo de homens e mulheres encontra-se já reunido em torno do delegado sindical. Progressivamente, vai-se fazendo silêncio. De onde decorre o plenário, avista-se a Triunfo. Outra fábrica-fantasma de paredes orgulhosamente erguidas. Outra fábrica enorme, vazia e silenciosa...

\footnotetext{
${ }^{1}$ Um agradecimento especial a Claudino Ferreira e a Hermes Costa pelas leituras atentas e enriquecedoras deste artigo.
} 
O plenário inicia-se. Trata-se de assinalar a data, de dar conta do que se passou nos últimos anos, das conquistas e das derrotas, das expectativas e das demoras, da definição de novas formas de luta. A palavra de ordem é "perseverança". Continuar a lutar. Não desistir. Não, agora, depois de tudo quanto se fez, de tanto tempo que se esperou. Há dívidas por saldar e feridas por sarar. Nos rostos dos ex-trabalhadores, o que perpassa, porém, é decepção e cepticismo. Cansaço, também. O cansaço das lutas vãs e das esperanças despedaçadas. ${ }^{2}$

A história da Estaco poderia contar-se em poucas linhas. Nascimento, vida e morte. Uma visão linear da sua trajectória que deixaria necessariamente escapar as vidas da vida da Estaco. As vidas que, como num eco, se prolongam para além da sua falência. Para uma grande parte dos trabalhadores, a falência da Estaco surge num momento crítico da sua trajectória de vida. ${ }^{3}$ Dizer que são "velhos de mais para arranjar trabalho e novos de mais para a reforma" tornou-se num lugar comum. Um lugar comum que adquire, porém, novos contornos quando se sabe que "a barreira dos 45 anos parece constituir o ponto de viragem no comportamento do mercado de trabalho face ao recrutamento" (Centeno, 2003: 43) e que os adultos de meia-idade constituem o grupo que maiores dificuldades encontra para ultrapassar uma situação de transição nos seus percursos profissionais (Centeno et al., 2001; Centeno, 2003; Rémillon, 2006). ${ }^{4}$ Anuladas a segurança e a estabilidade de um emprego que se julgava conservar até ao final da vida activa, o que resta àqueles que detêm escassos recursos de empregabilidade? De que forma é vivido o desemprego? De que forma os indivíduos organizam as suas vidas na sequência de um acontecimento desta natureza, um acontecimento, acima de tudo, complexo?

\footnotetext{
${ }^{2}$ Em Março de 2007, foi proferido acórdão do Supremo Tribunal de Justiça que não aplicou a norma contida no artigo $12 .^{\circ}$ do Decreto-Lei $.^{\circ}{ }^{\circ} 17 / 86$ que concede aos trabalhadores o privilégio creditório imobiliário geral com preferência sobre as hipotecas voluntárias, com fundamento na inconstitucionalidade da mesma. Desta forma, na graduação dos créditos relativamente aos imóveis, foram graduados, primeiro, o crédito dos bancos garantidos por hipoteca e só depois os créditos dos trabalhadores e do Fundo de Garantia Salarial. Resta agora, aos trabalhadores, o recurso ao Tribunal Constitucional.

${ }^{3}$ Os dados de que dispunha o Sindicato dos Trabalhadores das Indústrias de Cerâmica, Cimentos, Construção, Madeiras, Mármores e Similares da Região Centro permitiu traçar um perfil dos trabalhadores da Estaco. No momento da falência, estes situavam-se, maioritariamente, no grupo etário que vai dos 45 aos 60 anos; detinham um tempo de serviço na Estaco entre os 20 e os 30 anos; possuíam uma baixa escolaridade; e uma experiência de trabalho limitada quase exclusivamente à Estaco.

${ }_{4}$ À falta de melhor termo, na esteira de Centeno et al. (2001) designam-se por desempregados de meia-idade os indivíduos que se situam no grupo etário compreendido entre os 45 e os 54 anos e que acumulam desvantagens, simultaneamente, no plano da reinserção profissional e do acesso aos mecanismos legais de cessação da actividade.
} 
Partindo dos resultados de uma pesquisa sobre as experiências do desemprego dos ex-trabalhadores da Estaco ${ }^{5}$, procurarei dar conta de alguns dos factores que condicionam as vivências do desemprego, prestando particular atenção ao papel que o Estado social, enquanto mediador de compensação, desempenha na organização de estratégias de reacção/adaptação à privação de emprego.

\section{Modelo de análise das experiências do desemprego}

Para além da categoria de "desempregado", seja esta estatística, jurídica, administrativa, ou mesmo sociológica, encontram-se experiências do desemprego diferenciadas. O desemprego não corresponde a um estado, a uma condição estática que anule quer as diferenças entre desempregados, quer a heterogeneidade das suas experiências. Embora seja possível identificar características comuns às experiências do desemprego, o que a diversidade de trabalhos empíricos sobre esta temática tende a reforçar, é a extrema variedade de condições de desempregado e de maneiras de viver o desemprego (Lazarsfeld et al., 1981; Schnapper, 1994; Demazière e Dubar, 1997; Gallie e Paugam, 2000a; Rosa et al., 2001; Linhart et al., 2003; Rémillon, 2006).

As experiências do desemprego resultam, pois, do arranjo complexo de variáveis heterogéneas (Demazière, 1995: 101) e não será unicamente nas diferenças entre desempregados que deverão procurar-se as razões para a constatação empírica da heterogeneidade de vivências do desemprego. Para a análise das experiências do desemprego e das lógicas de acção desenvolvidas pelos desempregados para lidar com a privação de emprego, delineou-se, por isso, um modelo de análise que procurasse apreender a acção conjunta dos factores de vulnerabilidade e dos mediadores de compensação (Figura 1).

FIGURA 1 - Modelo de análise das experiências do desemprego

\begin{tabular}{|c|c|c|}
\hline Factores de vulnerabilidade intrínseca & & Factores de vulnerabilidade extrínseca \\
\hline & Factores de vulnerabilidade & \\
\hline \multirow[t]{2}{*}{ Experiências do desemprego } & & \multirow[t]{2}{*}{$\begin{array}{l}\text { Estratédias de reacção/adaptação } \\
\text { à privação de emprego }\end{array}$} \\
\hline & Mediadores de compensação & \\
\hline Estado social & Redes sociais & Actividades de substituição \\
\hline
\end{tabular}

${ }^{5}$ Pesquisa desenvolvida no âmbito de uma dissertação de Mestrado apresentada à Faculdade de Economia da Universidade de Coimbra (Araújo, 2006). 
Os factores de vulnerabilidade resultam da interacção entre factores de vulnerabilidade extrínseca, que se reportam aos espaços sociais de ancoragem das experiências do desemprego e aos efeitos de contexto (Demazière, 1995), e factores de vulnerabilidade intrinseca, que se reportam às características sociais dos indivíduos e às suas trajectórias profissionais. Os mediadores de compensação, por sua vez, dizem respeito às protecções asseguradas aos desempregados - principalmente pelo Estado social - e aos recursos mobilizáveis pelos desempregados - através, nomeadamente, das suas redes sociais - para fazer frente à privação de emprego. ${ }^{6}$

Tendo por base o modelo de análise, enunciou-se a seguinte hipótese de partida: as experiências do desemprego e as estratégias de reacção/adaptação à privação de emprego podem ser consideradas à luz da acção, a priori negativa, dos factores de vulnerabilidade e da acção, a priori positiva, dos mediadores de compensação. Assim, quanto maior for a probabilidade de os factores de vulnerabilidade extrinsecos e intrinsecos agirem cumulativamente e interactivamente como desvantagens, e quanto mais escassas forem as protecções mobilizáveis através dos mediadores de compensação, maior será a probabilidade de ver associado à situação de desemprego um conjunto de efeitos negativos, entre os quais se destacam o prolongamento do período de inactividade (desemprego de longa duração), a marginalização e/ou exclusão do mercado de trabalho, a privação financeira e a acentuação da dependência relativamente ao Estado social e/ou às redes sociais de apoio.

Na definição dos mediadores de compensação, inspirei-me no estudo comparativo de D. Gallie e S. Paugam (2000a, 2000b, 2000c) sobre as experiências do desemprego na Europa. Os autores partem da ideia de que a heterogeneidade das experiências do desemprego resulta dos efeitos diferenciados das relações entre estruturas: a) política (o Estado social); b) social (as protecções de proximidade); e c) económica (o mercado). O objectivo consiste em identificar o impacto destes factores de regulação do desemprego, salientando-se que, embora se possam isolar os seus efeitos particulares, será a configuração específica das suas interconexões que originará diferenças significativas nas vivências do desemprego. A configuração de experiências do desemprego mais ou menos excludentes resultará, pois, da acção dos modelos de regulação social do desemprego presentes em cada território nacional.

\footnotetext{
${ }^{6}$ L. Loison (2000) recorre à noção de mecanismos compensatórios do desemprego para se referir aos apoios prestados pela família e restantes redes sociais para colmatar os efeitos negativos do desemprego no contexto português de um semi-Estado-providência (Santos, 1993). Prefiro, pela minha parte, a noção de mediadores de compensação por me parecer mais apta a realçar que não se encontra subjacente à existência destes recursos e protecções uma sua activação automática em caso de necessidade.
} 


\section{Mediadores de compensação}

Para classificar a acção dos Estados-providência nacionais, D. Gallie e S. Paugam consideram exclusivamente a esfera de providência estatal ligada à protecção na eventualidade de desemprego. Os autores identificam, no âmbito europeu, quatro tipos de regimes de protecção (unemployment welfare regimes): 1) o regime subprotector (sub-protective); 2 ) o liberalmínimo (liberal-minimal); 3) o orientado para o emprego (employment-centered); e 4) o regime universal (universalistic). O regime de protecção no desemprego terá um efeito decisivo no tocante à privação financeira dos desempregados. Assim, num dos pólos encontra-se o regime universal - mais abrangente, com níveis de protecção mais elevados e por períodos mais longos - e, no pólo oposto, os regimes liberal-mínimo e subprotector, com níveis de protecção reduzidos e relativamente aos quais é de esperar a experiência de maiores dificuldades financeiras (Gallie e Paugam, 2000c: 352).

Segundo os autores, o tipo de regime de protecção mais próximo da realidade dos países do Sul da Europa (Portugal, Grécia, Itália e Espanha) é o subprotector, que se caracteriza pelos seguintes aspectos: o acesso às protecções depende fortemente da participação no mercado de trabalho; abrange um número reduzido de beneficiários; oferece um nível mínimo de protecção; as prestações são baixas; investe fracamente em políticas activas de emprego; é o regime com a maior probabilidade de originar dificuldades económicas; e tem uma elevada probabilidade de dilatar o período de desemprego (Gallie e Paugam, 2000b: 5).

O segundo factor de regulação social do desemprego reporta-se à protecção de carácter societal - solidariedades familiares e de proximidade - e baseia-se, por um lado, no grau de integração social dos desempregados e, por outro, na efectiva capacidade da providência societal para assegurar apoio material e/ou afectivo. A integração social levanta uma questão fundamental: a de saber se o desemprego se faz acompanhar de um enfraquecimento ou mesmo de uma ruptura com as redes sociais de apoio, passíveis de conduzir ao isolamento dos desempregados e de dificultar o acesso a diversas formas de apoio (materiais ou relativos a informações sobre oportunidades de emprego) (Gallie e Paugam, 2000c: 361).

Partindo da hipótese de que a natureza da estrutura familiar terá efeitos decisivos relativamente à protecção dos desempregados, o primeiro critério considerado diz respeito ao grau de estabilidade do modelo tradicional de família. Um segundo critério reporta-se às funções e responsabilidades atribuídas à família e à forma como a atribuição dessas funções e responsabilidades se articula com as políticas sociais dirigidas à família. O que os autores pretendem é relacionar dois princípios recorrentes nos exercícios 
de comparação dos regimes de bem-estar: a desmercadorização e a desfamiliarização. Num extremo, encontram-se sociedades com políticas sociais de maior investimento nos apoios institucionais à reprodução familiar e, no outro, sociedades onde a família permanece o principal mecanismo de providência, o principal mecanismo atenuador das insuficiências de assistência pública, e de eventuais falhas do mercado.

D. Gallie e S. Paugam avançam com três modelos para dar conta das funções e responsabilidades atribuídas à família. $\mathrm{O}$ modelo onde se inclui Portugal é o da dependência extensiva (extended dependence model). ${ }^{7}$ Nos países do Sul da Europa, a família surge como "um 'manancial' de solidariedades alternativas às do Estado" (Martin, 1995: 70). Sem que se estabeleça explicitamente um nexo causal, parece verificar-se uma correspondência entre desmercadorização e desfamiliarização: nos países em que existe uma maior abrangência das políticas sociais em diversos domínios, a dependência em relação à família faz-se mais ténue; naqueles onde as primeiras são mais restritivas e menos generosas, acentua-se a dependência relativamente à família. No caso da sociedade portuguesa, as lacunas de protecção abertas pelo regime subprotector encontram-se compensadas pela acção de uma sociedade-providência forte, o que aproximaria o modelo de regulação social do desemprego, em Portugal, do modelo familista. Parece importante, porém, que estes resultados sejam objecto de uma reflexão crítica à luz da realidade portuguesa.

Para Portugal, a primeira questão que se impõe é a de saber se à atribuição de responsabilidades às famílias corresponde a dotação de capacidades ou se nos encontramos perante um cenário onde, perante as falências do Estado social para garantir protecção aos seus membros, se reforça "uma visão moralizadora e moralizante da família, 'do que ela é e do que deve ser'” (Portugal, 2001: 329), que mais não faz do que acentuar as desigualdades. Situação que se torna tanto mais preocupante quanto se começa a verificar que as famílias detêm uma capacidade diferenciada para assumir as funções e responsabilidade que lhes são atribuídas (Wall, 2005; Vasconcelos, 2005), que se traduz, nalguns contextos sociais, numa inoperância da sociedade-providência (Hespanha e Portugal, 2002). Nas palavras de Boaventura de Sousa Santos (2001: 151), “o que parece preocupante na sociedade portuguesa é o facto [de as] solidariedades sociais estarem a desaparecer, ao mesmo tempo que se agravam as condições que as tornariam mais necessárias do que nunca”.

\footnotetext{
${ }^{7}$ Os restantes modelos são o da autonomia relativa entre gerações (relative inter-generational autonomy) e o da autonomia avançada entre gerações (advanced inter-generational autonomy). Encontram-se manifestações do primeiro em países como a França e a Bélgica, e do segundo em países como o Reino Unido, a Holanda, Alemanha, Dinamarca e Suécia.
} 
Finalmente, diferentemente do que acontece no modelo de análise proposto por D. Gallie e S. Paugam, as actividades de substituição ocupam o lugar do mercado (Figura 1). Estas consistem num leque de actividades que não se restringem aos maiores ou menores esforços individuais e às maiores ou menores probabilidades de retorno ao mercado de trabalho e são, por isso, susceptíveis de dar conta das estratégias individuais de reacção/adaptação desenvolvidas pelos indivíduos perante a privação de emprego.

O tempo do desemprego não consiste num tempo vazio em acontecimentos. As actividades de substituição permitem olhar para o lado activo dos desempregados (Capucha, 2000), lado activo que, por um lado, depende fortemente das margens de manobra individuais e que se joga, por outro, num espaço social concreto que marca as suas possibilidades tanto quanto as suas limitações. São estas actividades: 1) que se podem realizar à margem do mercado de trabalho; 2) que consistem num retorno a actividades anteriormente desenvolvidas em paralelo à actividade principal e/ou na prestação de serviços dentro e fora do agregado doméstico;3) desenvolvidas com a perspectiva de regressar diferentemente ao mercado de trabalho; e, finalmente, 4) de fraca vinculação ao mercado de trabalho.

O primeiro e o segundo tipo de actividades revêem-se fortemente no conceito multifacetado de economia informal. No entanto, enquanto as primeiras recaem no âmbito do trabalho não declarado ${ }^{8}$, já as segundas aproximam-se mais das actividades desenvolvidas pelo agregado familiar para seu uso pessoal. O que essa distinção pretende realçar é que "a 'economia informal' inclui não apenas transacções monetárias 'clandestinas', mas igualmente muitas outras formas de auto-produção que os indivíduos desenvolvem" (Hespanha e Portugal, 2002: 29). No âmbito da análise, estabeleceu-se, por isso, uma distinção entre trabalho não declarado, associado a actividades que se realizam informalmente no quadro da economia de produção, e actividades de autoprodução, que se realizam informalmente no quadro da economia de reprodução familiar.

O terceiro tipo de actividades pretende abranger as situações em que o desemprego 1) conduz a um investimento de e sobre si - por exemplo, na frequência de acções de formação profissional - de forma a regressar ao mercado de trabalho em condições distintas das de partida; 2) suscita a entrada numa actividade profissional completamente nova (reconversão profissional); e 3 ) abre a possibilidade para a criação do próprio emprego.

\footnotetext{
${ }^{8}$ Entendido como "qualquer actividade de carácter lícito, mas não declarada aos poderes públicos" (Comissão Europeia, 2004).
} 
Por último, as actividades de fraca vinculação ao mercado de trabalho aparecem por contraste a uma anterior vinculação forte (um contrato com duração indeterminada, um horário de trabalho completo e regulado por contratação colectiva, um determinado local de trabalho, a possibilidade de progressão numa carreira profissional e uma concepção hierárquica e colectiva das relações de trabalho, etc.). A fraqueza da vinculação ao mercado de trabalho permite dar conta da armadilha do desemprego, um ciclo vicioso marcado pelo emprego-desemprego-emprego desencadeado pela perda de emprego num momento chave do percurso profissional dos indivíduos. ${ }^{9}$ As actividades de fraca vinculação implicam uma abordagem metodológica longitudinal que não foi a privilegiada no âmbito desta análise. No entanto, pareceu importante inclui-las pelo facto de, para os desempregados da Estaco, aparecerem como as modalidades de emprego que mais contrastam com a experiência profissional anterior e que, dadas as circunstâncias, aparecem mais recorrentemente como as modalidades de emprego possiveis em termos de perspectivas para o futuro.

\section{A Estaco: visões e desilusões}

Esboçadas as grandes linhas que compõem o modelo de análise das experiências do desemprego, regressemos à Estaco. Volvidos quatro anos sobre a falência da Estaco, conduzimos uma série de entrevistas em profundidade com ex-trabalhadores que se encontravam então em situação de desemprego, com o objectivo de identificar, primeiro, quais os obstáculos à sua reintegração profissional e, segundo, quais as lógicas de acção desenvolvidas pelos desempregados para lidar com o desemprego. ${ }^{10}$

\footnotetext{
${ }^{9}$ Por armadilha do desemprego entendem-se os percursos marcados pelo que I. Kovács (2005) designa de flexibilidade precária estável: um tipo de percurso que se caracteriza, entre outros aspectos, por mudanças frequentes de empregos flexíveis, na maioria precários, e por, relativamente às perspectivas profissionais, ser marcado pela instabilidade a longo prazo, pela precariedade e pela ameaça do desemprego. A autora distingue ainda dois outros tipos de flexibilidade: a flexibilidade qualificante - que se caracteriza pelos seguinte aspectos: "emprego flexível por opção por um certo modo de vida; trabalho altamente qualificado, permitindo e exigindo aprendizagem contínua; posição e capacidade de negociação dos indivíduos com o empregador; forte mobilidade profissional no mercado de trabalho externo (entre empresas); perspectivas profissionais: actividade profissional intensa e qualificante, ligação às empresas sem vínculos estáveis" (Kovács, 2005: 64) - e a flexibilidade precarizante transitória - emprego flexível transitório de jovens com níveis de educação elevados/médios cujo trabalho tende a ser pobre em conteúdo limitando o uso das suas qualificações e aprendizagem no trabalho; falta de capacidade de negociação com o empregador; estão à espera de um emprego melhor; querem diversificar a experiência profissional ou obter um rendimento complementar; têm grande esperança e procuram uma situação profissional melhor" (ibid.: 63).

${ }^{10}$ Foram conduzidas dezasseis entrevistas, dez das quais com homens e as restantes com mulheres. Partindo dos dados de que dispunha o Sindicato dos Trabalhadores das Indústrias de Cerâmica, Cimentos, Construção, Madeiras, Mármores e Similares da Região Centro, construímos uma base
} 
A falência da Estaco insere-se num processo que demoraria seis anos a completar-se. Foi este um tempo vivido sob o signo da incerteza e da apreensão quanto ao destino da Estaco, com expectativas e esperanças a serem sucessivamente criadas e goradas, alimentadas e frustradas. Não será, pois, de estranhar que, nalgumas entrevistas, a falência da Estaco, embora sempre reconhecida como trágica, apareça igualmente como uma libertação. Libertação, acima de tudo, relativamente à incerteza. Há nas entrevistas um marcado sentido de "dever cumprido" e um notório cansaço derivado de "uma vida de trabalho e dedicação" que acaba abruptamente. ${ }^{11}$ A reforma era a meta e a falência da Estaco uma "injustiça". Outro dado recorrente nas entrevistas é a perplexidade. $\mathrm{Na}$ origem desta perplexidade encontram-se diversos elementos: a antiguidade da fábrica; a importância da Estaco nos âmbitos sectorial e nacional; a sua dimensão e implantação no mercado; as expectativas que nela depositavam os trabalhadores. Todos estes elementos combinam-se para criar uma imagem da Estaco de solidez, de estabilidade, que torna difícil acreditar que esta poderia um dia cessar de existir. Segurança e estabilidade podem, de facto, funcionar como uma cidadela que se constrói em torno da vida sem se dar conta de que, com o correr do tempo, se torna cada vez mais difícil abandoná-la.

Com os ex-trabalhadores da Estaco, estamos perante um grupo cuja experiência do desemprego deve ser lida à luz de uma experiência profissional profundamente marcante. A experiência de trabalho na Estaco representa, nalguns casos, a única, e, em todos eles, a experiência de trabalho mais significativa. O desemprego representa, pelo contrário, uma novidade com a qual tiveram de aprender a lidar à medida que se foi prolongando. Será sempre por oposição à situação anterior, o trabalho na Estaco, que será avaliada a situação actual, o desemprego. Interrogados sobre aquilo de que sentem mais falta em relação à Estaco e sobre as principais alterações nas suas vidas originadas pelo desemprego, nas respostas encontra-se sempre este contraste entre presente e passado. É este que melhor permite medir, por um lado, a amplitude que assumem as mudanças na sequência do desemprego e, por outro, a incerteza que a ruptura com um emprego estável veio trazer. Viver para o presente quando se tinha um trabalho que permitia alguma projecção no futuro será, talvez, um dos elementos mais marcantes

de dados onde constavam 264 ex-trabalhadores. Tendo em conta a sua situação no momento da análise, foram excluídos 103 ex-trabalhadores que se reformaram quando do encerramento da fábrica ou posteriormente a este. Restava, deste modo, uma população de 161 ex-trabalhadores. Destes excluímos 33 relativamente aos quais não foi possível apurar a situação e 90 que, à data da recolha de dados, se encontravam empregados. O nosso universo de partida era, assim, composto por 38 desempregados. As entrevistas foram conduzidas entre Novembro e Dezembro de 2005. ${ }_{11}$ As expressões entre aspas são retiradas dos discursos dos desempregados. 
nas experiências do desemprego dos ex-trabalhadores da Estaco: "Porque isto é a mesma coisa do que uma pessoa ir a subir a escada da vida e já estar num certo patamar e, de repente, levar um abanão e vir ter cá em baixo" (E10, Homem, 49 anos, Desenhador). ${ }^{12}$

A falência da Estaco representa o fim de um tempo e a necessidade de adaptação a uma nova vida. Previsivelmente, a dimensão financeira é aquela que assume maior destaque: consome-se menos, tem-se mais cuidado, corta-se no que se pode cortar, abdica-se do que se pode abdicar. As mudanças originadas pelo desemprego vão, porém, mais longe do que a privação financeira. O desemprego veio romper laços de amizade forjados na fábrica, interromper sociabilidades e isolar os ex-trabalhadores. $\mathrm{O}$ desemprego veio quebrar hábitos adquiridos, uma rotina estabelecida. Veio adiar projectos (obras na casa, mudar de carro, etc.). Uma vez mais é o peso do presente que se faz sentir. É o controlo sobre a sua própria vida que escapa.

$\mathrm{Na}$ grande maioria dos relatos, o primeiro ano de desemprego aparece como o mais difícil. É neste primeiro ano que, progressivamente, se vai ganhando consciência de que o regresso à Estaco é improvável e que será difícil, senão impossível, encontrar um emprego que se aproxime daquele que se detinha anteriormente. A Estaco fechou e não voltará a abrir. Perante esta evidência, torna-se necessário avaliar as condições objectivas de que se dispõe para enfrentar a situação de desemprego. E é então que começam a tornar-se evidentes os efeitos dos factores de vulnerabilidade.

\section{Factores de vulnerabilidade}

Os entrevistados tendem a fazer uma leitura que não autonomiza a acção de qualquer um dos elementos constitutivos dos factores de vulnerabilidade, mas antes procura reforçar a sua acção conjunta. Assim, a idade, os baixos níveis de habilitações, a sobre-especialização, a dificuldade de reconversão, etc., aparecem como factores de vulnerabilidade intrinsecos porque interagem com diversos, e muitas vezes difusos, factores de vulnerabilidade extrínsecos: o desemprego generalizado, a situação do mercado de trabalho, geral e local e do sector de origem, em particular, a "crise", etc. O que os entrevistados tendem a realçar é a escassez de oportunidades no âmbito local para um segmento da população oriundo de um sector de actividade específico. Escassez de oportunidades que se agrava com a idade, percepcionada e vivida como um obstáculo à reinserção no mercado de trabalho e como um factor importante de prolongamento do período de desemprego. A Estaco torna patente a forma como, por um lado, história industrial local (Reis,

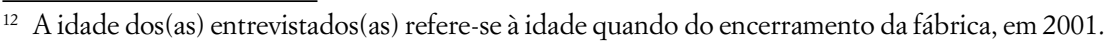


1992) e histórias pessoais podem entrelaçar-se e, por outro, o modo como a fragilização territorial, evidenciada pelas perdas registadas no tecido industrial local (Conselho da Cidade, 2004), pode traduzir-se na fragilização das condições de existência de determinados segmentos da população. É precisamente aqui que o universo de oportunidades contidas no espaço onde o desemprego é vivido se cruza com as características sociais dos indivíduos e as suas trajectórias profissionais, agindo como desvantagens. A percepção que os entrevistados têm relativamente a este dado é, aliás, bastante lúcida. Revelam-se conscientes das transformações em curso no plano local e da reduzida probabilidade de regressar "àquilo que se sabe fazer", assim como das reduzidas possibilidades de encontrar um emprego cujas condições se aproximem do ideal forjado pela extensa experiência de trabalho anterior. A acção dos factores de vulnerabilidade faz-se, pois, sentir na escassez de oportunidades de regresso no mercado de trabalho - ou, pelo menos, de regresso em condições que se aproximem das de origem -, agravando-se essa escassez à medida que se prolonga o período do desemprego.

A idade constitui o factor mais referido pelos entrevistados para evidenciar as dificuldades de regresso a um mercado de trabalho que se revela particularmente hostil a pessoas que ultrapassem um determinado patamar etário. ${ }^{13}$ Se o regresso àquilo que se sabe fazer parece improvável, nas entrevistas percebe-se a dificuldade que representa abdicar de um saber fazer, de uma carreira profissional conquistada paulatinamente sem outras bases que não a experiência, ou seja, com a tomada de consciência de que uma experiência de trabalho adquirida ao longo da vida pode tornar-se subitamente inútil.

Parece que foi uma borracha que passou e apagou tudo. Toda a minha experiência profissional foi ao ar. A primeira vez que eu fiz o currículo [...] fiquei a olhar para aquilo e... Era como se uma esponja passasse ali. Tive que rasgar aquilo e fazer outro. O choque foi de tal maneira... Se alguém olhasse para aquilo pensava: "Ela entrou na Estaco, ficou na Estaco, esperou que aquilo fechasse e veio-se embora!". (E2, Mulher, 42 anos, Analista $1^{a}$ )

O que as entrevistas parecem revelar é que os factores de vulnerabilidade tendem a amplificar as incertezas ao mesmo tempo que limitam as opções de saída. Torna-se, deste modo, compreensível que o ideal da reforma nunca

${ }_{13}$ Fonte de discriminação, a idade surge, todavia, igualmente como um elemento protector relativamente à atribuição de uma responsabilidade individual por uma situação não desejada de retirada precoce do mercado de trabalho. 
abandone o imaginário dos entrevistados, na medida em que a certeza de um rendimento fixo proporcionado pela reforma é a situação que mais se poderia aproximar da situação anterior.

A idade desempenha aqui, uma vez mais, um papel fundamental, já que apenas uma parte dos entrevistados terá a possibilidade de aceder a este mecanismo socialmente reconhecido de interrupção da vida activa e de inactividade. Estabelece-se aqui uma cisão entre aqueles que podem continuar a prosseguir o ideal da reforma e aqueles que, para atingir esse fim, se vêm na obrigação de regressar ao mercado de trabalho. Este será um aspecto decisivo para compreender a forma como, com o prolongamento do período de desemprego, se começam progressivamente a delinear modos de adaptação e estratégias de resolução distintos e relativamente aos quais os mediadores de compensação desempenham um papel fundamental.

\section{Mediadores de compensação e lógicas de acção dos desempregados}

Os mediadores de compensação reportam-se às protecções e recursos assegurados e mobilizáveis pelos desempregados para fazer frente à situação de desemprego. A hipótese subjacente aos mediadores de compensação é a de que estes - agindo isoladamente ou em articulação, temporariamente ou de forma mais prolongada - podem conferir aos desempregados protecções e recursos diferenciados e, nessa medida, suscitar vivências do desemprego mais ou menos integradas e vividas de modo mais ou menos autónomo ou dependente.

\subsection{Estado social}

$\mathrm{Na}$ esteira de D. Gallie e S. Paugam (2000a), foi considerada a esfera de providência estatal ligada à protecção na eventualidade de desemprego e os seus efeitos na privação financeira e para autonomia/dependência dos desempregados. No entanto, a par da privação financeira, pareceu importante considerar igualmente a avaliação e as expectativas dos entrevistados relativamente à acção dos serviços públicos de apoio (Centros de Emprego). O que se verifica é que, apesar da heterogeneidade de percursos institucionais (Figura 2), encontra-se alguma unanimidade na avaliação e nas expectativas dos desempregados em relação à acção dos serviços e às compensações sociais garantidas pelo Estado.

No percurso institucional dos desempregados, a semelhança mais flagrante encontra-se no acesso à prestação de subsídio de desemprego.${ }^{14}$ No

\footnotetext{
${ }_{14}$ Perante as circunstâncias em que surge o desemprego esta seria, de resto, uma situação esperada, já que todos os ex-trabalhadores da Estaco cumpriam os requisitos necessários - relação laboral, situação de desemprego e prazos de garantia - para beneficiar do subsídio de desemprego.
} 


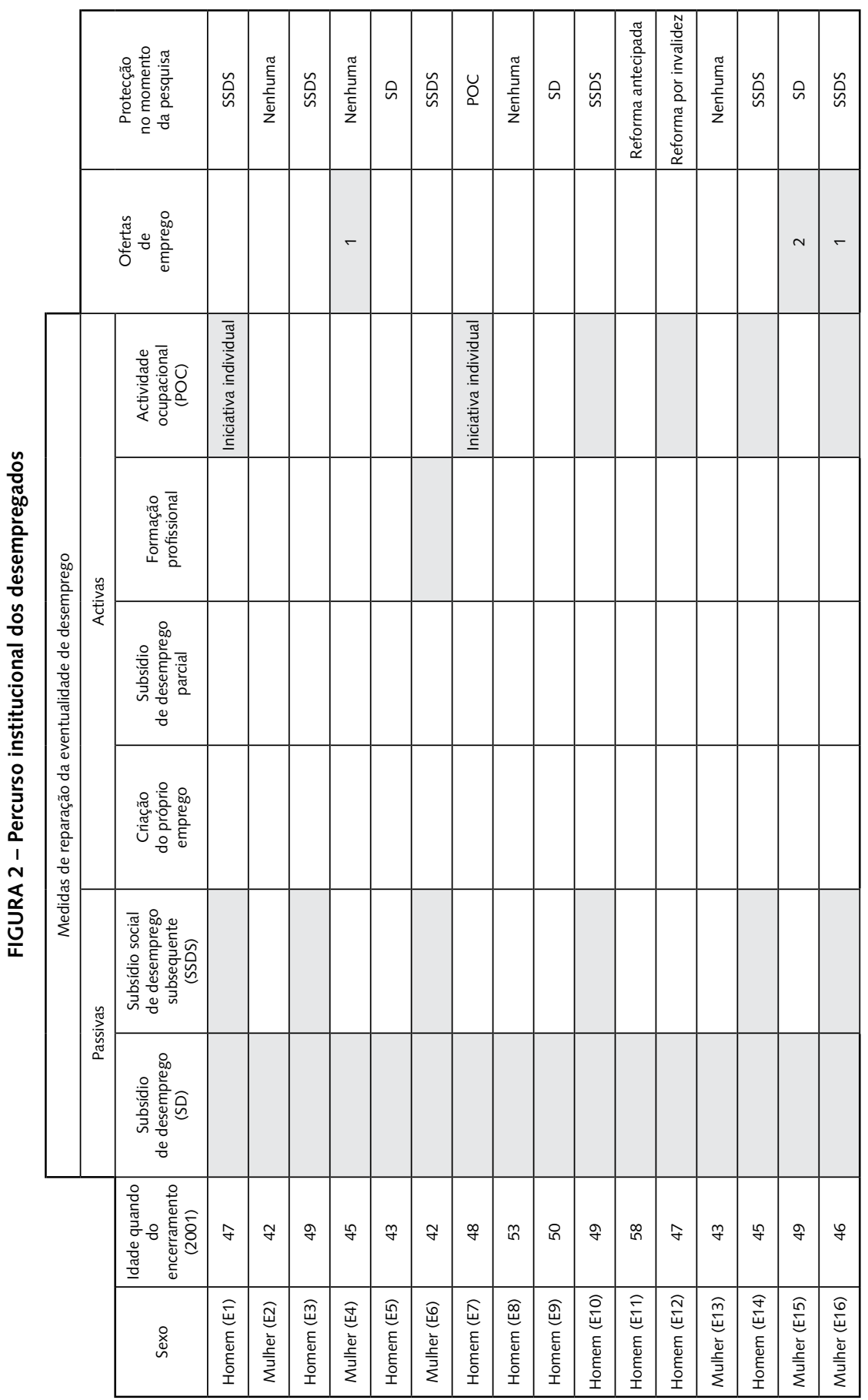


que diz respeito ao montante do subsídio, variando este em função do valor da remuneração de referência, a avaliação dos entrevistados aponta tendencialmente para considerar o montante insuficiente. Não obstante, mesmo quando avaliadas como baixas, as prestações de desemprego representam uma fonte de rendimento fixa e segura e, por isso, a fonte de rendimentos que mais se aproxima da situação anterior (o salário).

Para as medidas ditas activas, são os Programas Ocupacionais (POC) que assumem maior destaque. Porém, apenas uma parte dos entrevistados participou em POC, sendo de realçar que em dois casos foram os próprios desempregados que procuraram as instituições onde realizaram as ocupações temporárias. Nos restantes casos, tratou-se, por um lado, de "ocupar" o tempo do desemprego e, por outro, de dar cumprimento às imposições legais impostas aos beneficiários, já que, na óptica dos entrevistados, nem as ocupações correspondiam às expectativas, nem ofereciam quaisquer perspectivas de permanência para além do programa. As críticas dirigidas aos POC variam em função da ocupação desenvolvida. Todavia, existe algum consenso no que diz respeito ao carácter temporário destas ocupações, às condições de trabalho, e à verdadeira utilidade destas ocupações socialmente úteis.

Disseram que quando acabasse o desemprego que logo se via [possibilidade de permanecer na instituição onde desenvolveu o POC], mas o que acontece é que eles vão logo buscar outra ao desemprego. Aquilo torna-se um círculo vicioso, está a perceber? Têm o trabalho feito à conta das pessoas que estão no desemprego e só lhes dão o subsídio de transporte e o subsídio de alimentação. [...] Aquelas que lá ficaram foi só para quatro horas. E isto é que me... Quer dizer quando a gente anda lá a trabalhar e são os outros a pagar, há trabalho para oito horas, quando são eles a pagar já só há trabalho para quatro horas! Depois as pessoas dizem que os desempregados só não trabalham porque não querem, mas não é bem assim! Dizem que quem quer trabalhar arranja sempre emprego, mas não é! Dizem que se a gente mostrar empenho e cumprir a nossa obrigação que fica lá, mas não fica! Não sou só eu que vi isto. As outras que lá andaram, quando chegou a altura vieram-se embora. "Vai-te embora e mete-se outra!". A gente não pára em lado nenhum! (E16, Mulher, 46 anos, Escolha Linha Auto)

Outro dado importante a apontar é o facto de apenas em três casos os entrevistados terem sido objecto de ofertas de emprego por parte dos respectivos Centros de Emprego. Tal parece reforçar os resultados da pesquisa de L. Centeno et al. (2001) sobre as dificuldades acrescidas de reinserção no mercado de trabalho que enfrentam os desempregados de meia-idade. 
À medida que se prolonga o período de desemprego, tendem a desvanecer-se as expectativas dos desempregados relativamente aos agentes públicos e a endurecerem-se as críticas dirigidas à sua acção. Ainda no que diz respeito às colocações, uma outra fonte de crítica prende-se com a qualidade dos empregos. De facto, estes não arriscam a estabilidade que representam as prestações de desemprego, por um regresso ao mercado de trabalho em condições precárias ou mesmo para criar o próprio emprego. A aversão ao risco, extremamente recorrente nas entrevistas, exprime a consciência da situação de fragilidade e de insegurança aberta pela falência da Estaco e da escassez de recursos, nomeadamente em termos de empregabilidade. Associado à aversão ao risco, o Estado social, enquanto mediador de compensação, assume-se como a figura central na economia das protecções (Castel, 2003) dos desempregados.

O Estado social representa, agora, o grande integrador, substituindo-se a uma função que o mercado de trabalho não parece já em condições de desempenhar. A dependência relativamente ao Estado social aparece, assim, como uma dependência consentida por parte dos serviços públicos (expressão da sua incapacidade para encontrar soluções que passem pelo reemprego) e uma dependência legítima por parte dos desempregados (pela mesma razão e por ter sido involuntária a retirada precoce do mercado de trabalho). No que diz respeito aos apoios garantidos pelo Estado na eventualidade do desemprego, as lógicas de acção dos desempregados passam, pois, pela tentativa de maximizar o período de abrangência pelas protecções sociais. Essas lógicas encontram eco nos mecanismos institucionais de apoio (maxime Centros de Emprego), que resumem a sua acção ao cumprimento das suas obrigações legais e, em particular, à sua função redistributiva.

É acima de tudo este aspecto que reforça o carácter subprotector do regime de protecção no desemprego. Limitando-se a cumprir a sua parte, o Estado traça os limites da sua intervenção ao mesmo tempo que traça os limites da sua responsabilidade. Dependência consentida e dependência legítima delimitam, num mesmo movimento, as fronteiras daquilo que se pode fazer e daquilo que se pode esperar. O regime de protecção no desemprego aparece como subprotector, na medida em que, como parece ser aqui o caso, promove uma protecção social, inteligível nas práticas dos serviços públicos de emprego e nas lógicas de acção dos desempregados, que coloca maior ênfase em medidas de reparação passivas em detrimento das políticas activas (Hespanha, 2005) e que apresenta baixos níveis de exigência relativamente aos desempregados.

O regime de protecção no desemprego parece ser, aqui, resignado. A resignação é, porém, extensível aos desempregados. Com o prolongamento do 
desemprego, começa a tornar-se claro que o mercado de trabalho constitui uma meta cada vez mais inatingível, pelo que é ao Estado social que se atribui a responsabilidade por garantir o apoio material sonegado pela falência da Estaco. À "injustiça” que representou a falência da Estaco, deve o Estado responder com justiça, garantido a protecção anteriormente assegurada pelo trabalho. Daí que sejam sentidas como ilegítimas quaisquer tentativas por parte dos serviços para aplicar de forma rígida as obrigações subjacentes às medidas de reparação e como injustas as sanções por incumprimento dos deveres.

[No Centro de Emprego] ofereceram-me um emprego [...], mas eu disse que não podia ir porque era muito longe. Já não tenho idade, nem capacidade. Eu estava muito traumatizada. Isto foi sete meses depois de ter ficado no desemprego... E eu disse-lhes que era muito complicado e eles disseram-me que eu era obrigada a aceitar, mas eu disse que não. Para a zona de Coimbra ou de Coimbra para cá, eu aceitava porque eu queria trabalhar e preciso de trabalhar pelo menos mais dez anos, mas assim não. E simplesmente riscaram-me logo. [...] Foi horrível mesmo. Trabalhei trinta anos, só tive direito a desemprego sete ou oito meses [...]. Nunca mais lá fui [Centro de Emprego]. [...] Eu descontei trinta anos! Sempre fui uma pessoa assídua e pontual. [...] Foi muito chato. Eu acho que eles não o deveriam ter feito. Podiam-me ter dado mais uma chance, mas pronto, eles é que mandam. [...] Estavam-me a dar um emprego e eu era obrigada a ir. Mas era impossível. [...] Senão eu tinha ido. Não estava aqui neste dia-a-dia. Nem pensar. Eu tinha ido. [...] Assim, olhe, não tenho nada de bom para contar e se calhar até tinha. Era mais um tempo de trabalho e depois vinha para o desemprego se eles me mandassem embora e ia assim empatando. Mas não. [...] Fiquei logo sem nada! Só recebi sete ou oito meses. É pouco. (E4, Mulher, 45 anos, Escolha Linha Auto)

\subsection{Redes sociais}

No caso dos ex-trabalhadores da Estaco, o desemprego é vivido, sobretudo, no seio da família nuclear ( grupo doméstico de família simples), pelo que as solidariedades familiares se atêm, quase exclusivamente, às relações entre os membros do casal. ${ }^{15}$ As dependências financeiras são relativas ao/à cônjuge e acentuam-se quando finda o período de concessão das prestações de

\footnotetext{
${ }^{15}$ Registamos apenas uma excepção, onde a entreajuda se estende à família directa por via da ascendência da mulher do casal, numa lógica - consentânea com os resultados de uma pesquisa de larga escala sobre as redes sociais de apoio (Wall, 2005) - de dominância da matrilinearidade nos apoios familiares (Vasconcelos, 2005). A grande limitação deste tipo de entreajuda prende-se com a mobilidade geográfica dos desempregados. As solidariedades primárias têm uma bistória, são personalizadas e territorializadas, nas palavras de J. A. Nunes (1995: 7), pelo que ao conferir protecção acentuam, simultaneamente, a dependência relativamente ao seu espaço de ancoragem.
} 
desemprego. O Estado social exerce, pois, uma função de complementaridade, nos casos em que os desempregados continuam a beneficiar das prestações de desemprego, e o/a cônjuge e/ou a família uma função de substitutibilidade, nos casos em que cessa o direito às prestações.

Além disso, encontram-se nas entrevistas, principalmente nas entrevistas com mulheres, evidências de uma fragilização da acção providencial das famílias. É essencialmente por via das mulheres que se fazem os apoios familiares (Vasconcelos, 2005; Portugal, 2006), pelo que o desemprego, embora represente uma maior disponibilidade de tempo por parte das mulheres, diminui efectivamente as possibilidades de se prestar auxílio financeiro.

- Entrevistador: Não tem nada de positivo estar no desemprego?

- E. P.: Tem a minha netinha. Que me ajuda a divertir e eu ajudo a criá-la. Só. Mas depois tenho a falta que me faz mais falta que é o dinheiro. A gente sem dinheiro não faz nada, não é? O que é que tenho de bom? [...] Eu tinha tudo preparado. Ela teve a menina em Dezembro e a fábrica fechou em Outubro. E eu que dizia: "Ó filha, depois ajudo-te, a menina vai para o colégio, vai para a ama”, qual ajuda qual quê! Com uns míseros tostões lá do [subsídio de] desemprego, era com isso que a ajudava? E depois ficámos sem fundos. Estivemos algum tempo sem receber e, portanto, tivemos que ir buscar o dinheiro aonde o tínhamos. Para comer... Todos os meses se gastava... Foi uma situação muita má. [...] A minha filha comprou uma casa e nós gostávamos muito de poder ajudar, mas com quê? Com noventa contos que o meu marido ganha. Aquele que a gente tinha, durante o tempo em que estivemos desempregados, fomos lá buscar quase tudo... Não se ganhava, mas gastava-se na mesma. Foram uns meses horríveis que a pessoa ali passou. (E4, Mulher, 45 anos, Escolha Linha Auto)

As redes sociais não parecem funcionar como um mediador de compensação em si mesmo suficiente para proporcionar aos desempregados vivências do desemprego mais autónomas. Pelo contrário, quando não articuladas com as compensações financeiras providenciadas pelas medidas de reparação estatais, a dependência familiar parece acentuar a tirania da dependência, esta, apesar de tudo, menos pacífica do que a dependência relativamente ao Estado social, que assume aqui um carácter legítimo. O Estado social continua a ser perspectivado como o único capaz de atenuar os efeitos do desemprego, principalmente em termos de privação financeira e de garantia de autonomia. Era um rendimento fixo, a segurança, que tornava os trabalhadores dependentes da Estaco. É por idêntica razão que os ex-trabalhadores ambicionam, agora, tornar-se dependentes do Estado. 


\subsection{Actividades de substituição}

As actividades de substituição remetem para estratégias de adaptação/reacção à privação de emprego que não se atêm exclusivamente ao mercado. A inclusão na análise das vivências do desemprego das actividades de substituição afigura-se tanto mais importante quanto, como é aqui o caso, a empregabilidade dos desempregados se encontra fortemente condicionada pelos factores de vulnerabilidade, intrínsecos como extrínsecos.

\section{A armadilha do desemprego}

Perante um mercado de trabalho onde não encontram lugar e redes sociais incapazes de garantir protecção, porque frágeis ou apenas capazes de reforçar as dependências, quais são as alternativas que restam aos desempregados? Se não parecem existir mostras de qualquer pressão exercida sobre os desempregados para reencontrar emprego, nem por parte dos serviços públicos, nem por partes das famílias, a pressão financeira, esta sim, é uma realidade. Acentuando-se a tirania da necessidade, começa a ganhar contornos a forma como se poderá vir a tecer a armadilh a do desemprego, com a idade a afirmar-se como uma variável crucial. A distinção faz-se aqui entre os desempregados que beneficiam de uma situação familiar mais estabilizada (com descendentes em situação de independência total ou parcial) e que, por força da idade ou por questões de saúde, alimentam a perspectiva de aceder a um outro tipo de protecção social (a reforma antecipada ou por invalidez); e aqueles que acumulam situações familiares menos estabilizadas (descendentes dependentes) com a necessidade de reingressar no mercado por necessidade e para poder continuar a "descontar" e alimentar o ideal da reforma.

Será este grupo que, impossibilitado de reclamar mais Estado, ficará mais exposto às contingências de um mercado de trabalho pouco receptivo à sua entrada. A estratégia dos primeiros passa, assim, por maximizar as protecções, prolongando a sua duração até conseguir "meter os papéis para a reforma”. Enquanto os segundos procuram, num primeiro tempo, prolongar o período das prestações e, num segundo, uma saída viável nesta busca pela estabilidade perdida. Por saida viável, entende-se um emprego que thes permita continuar a efectuar descontos e completar, deste modo, o objectivo de chegar à reforma "com alguma coisa" ou que lhes permita aceder, de novo, às prestações de desemprego. Embora não descurando a possibilidade de alternar períodos de emprego com prestações de desemprego, a qualidade dos empregos revela-se aqui mais importante do que no primeiro caso, já que o ideal da reforma se situa num horizonte relativamente mais distante. Perante a falta de alternativas, procura-se ganhar tempo. Ganhar tempo para, finalmente, chegar ao fim de um percurso laboral que vai já longo. 


\section{Regressar diferentemente ao mercado de trabalho}

Relativamente à formação profissional, que integra o grupo das actividades desenvolvidas com a perspectiva de regressar diferentemente ao mercado de trabalho, verificou-se em apenas dois casos. Num dos casos, tratou-se de uma formação profissional, promovida por uma IPSS local, cujo objectivo final era a constituição de uma empresa de inserção. A participação da entrevistada nesse curso insere-se claramente numa lógica de mero cumprimento dos deveres legais e de tentativa de prolongamento do período de concessão das prestações de desemprego, já que a avaliação, para além de francamente negativa, é igualmente reveladora da aversão ao risco patente na generalidade das vivências do desemprego. Esta situação contrasta com a outra experiência, protagonizada igualmente por uma mulher, em que a formação profissional aparece por iniciativa de uma desempregada que não beneficia já de qualquer protecção social e que se encontra na dependência do cônjuge. As sucessivas formações profissionais frequentadas inserem-se, estas sim, nas actividades que visam regressar diferentemente ao mercado de trabalho. A reconversão profissional surge, acima de tudo, como um imperativo de sobrevivência e o abandono da profissão como algo doloroso, mas necessário.

\footnotetext{
Portanto tudo o que vai aparecendo nesta área, eu faço [formações profissionais na área do cuidado a crianças]. Sou uma pessoa que gosta de perceber aquilo que estou a fazer e estar a fazer as coisas no ar para mim não é bom. Assim, como já tenho um curriculum muito grande nesta área [desde que ficou no desemprego frequentou cinco acções de formação subsidiadas], sempre que aparece alguma coisa no jornal vou-me inscrevendo, pronto, sempre na esperança de arranjar alguma coisa, de arranjar um horário, um ordenado. Pronto, mudar a situação. Voltar à situação em que estava, não é? (E2, Mulher, 42 anos, Analista $1^{\text {a)}}$
}

\section{Trabalho não declarado, actividades paralelas e prestação de cuidados}

As experiências do desemprego não se desenrolam no vazio. Com o prolongamento do período de desemprego os indivíduos parecem deslizar para novas rotinas. $\mathrm{O}$ encerramento da fábrica constitui, de facto, um choque, uma ruptura violenta com uma rotina estabelecida. O primeiro ano de desemprego parece ser, na maioria dos casos, o mais difícil, aquele onde a perda da rotina se faz sentir com maior acuidade. Com o correr do tempo, porém, novas rotinas se vão forjando. Especial enfoque vai para as actividades que se podem realizar à margem do mercado de trabalho; para aquelas que consistem num retorno a actividades anteriormente desenvolvidas em paralelo à actividade principal numa lógica de diversificação económica; e para a prestação de serviços dentro e fora do agregado doméstico. 
A percepção que os ex-trabalhadores da Estaco têm relativamente ao trabalho não declarado mais não faz do que reforçar a constatação da aversão ao risco e que o Estado social desempenha de facto uma posição central na organização dos mediadores de compensação e das estratégias individuais. Do ponto de vista da grande maioria dos entrevistados, o trabalho não declarado não oferece quaisquer vantagens. ${ }^{16}$ As prestações de desemprego aparecem como uma segurança que não se arrisca para realizar actividades do tipo não declarado. Para além de constituir um risco - já que pode conduzir à anulação das prestações e à reposição dos montantes já auferidos -, o trabalho não declarado impede, igualmente, que se continue a "descontar para a Segurança Social", ou seja, que se prossiga o objectivo de reunir as condições necessárias para a beneficiar da reforma.

Diferentemente percepcionadas pelos entrevistados são as actividades que se desenvolvem no quadro da economia de reprodução familiar. No âmbito destas actividades assumiram particular destaque, para os homens, a pequena agricultura e, para as mulheres, o cuidado a crianças.

$\mathrm{O}$ regresso à pequena agricultura não representa verdadeiramente um regresso, uma vez que, a par do trabalho na fábrica, esta sempre fez parte das estratégias de diversificação económica dos trabalhadores (Piselli, 1995). A "terra" aparece, assim, particularmente valorizada, quer por aqueles que não têm acesso a ela, quer por aqueles que a trabalham. A terra continua a ter um valor simbólico que ladeia o seu valor material. Encontra-se nos entrevistados uma hipervalorização do fundiário, baseada nas funções materiais por este desempenhadas, que vai de par com uma sua, não menos importante, função securizante e integradora (Hespanha, 1994: 70 ss.).

A pequena agricultura continua a desempenhar um efeito de compensação (Reis, 1985, 1993) relacionando-se, desta feita, não já com os baixos salários, mas com as prestações de desemprego. Com o desemprego, intensifica-se o trabalho na agricultura. É a escassez de recursos disponíveis que determina a centralidade da pequena agricultura, que, porém, "não dá dinheiro". Tal como acontece com a prestação de cuidados, é uma actividade de substituição precária, que deve continuar a manter o seu carácter complementar, se já não com uma actividade remunerada, pelo menos com as compensações financeiras garantidas pelo Estado. ${ }^{17}$

\footnotetext{
${ }^{16}$ No único caso registado de trabalho não declarado, o que se verifica é que, tratando-se de uma modalidade flexível de emprego que em nada se aproxima da situação anterior, as prestações de desemprego representam uma segurança de que não se abdica para exercer uma actividade precária. ${ }_{17} \mathrm{Tal}$ como acontece com as mulheres, também os homens, mesmo encontrando na pequena agricultura uma fonte de resistência aos efeitos desestabilizadores e estigmatizantes do desemprego, prefeririam manter uma actividade remunerada permanente. A uma forte ética do trabalho associa-se, não o esqueçamos, uma forte dependência relativamente ao trabalho para assegurar a subsistência.
} 
Do lado das mulheres, a prestação de cuidados a crianças (aos netos, na maior parte dos casos) aparece como algo vivido de forma ambígua: como positivo, já que permite preencher um vazio aberto pela falência da Estaco; e como negativo, na medida em que a falência da Estaco veio reduzir a possibilidade de se prestar auxílio financeiro. O que a prestação de cuidados de proximidade vem realçar é o facto de o desemprego feminino, envelhecido e desqualificado, acentuar a vinculação feminina ao espaço doméstico. Ou seja, opera-se, pelo viés do desemprego, um refluxo das mulheres em direcção à esfera doméstica.

As implicações do desemprego, no caso das desempregadas cujo perfil se aproxime daquele aqui traçado, não podem ater-se à privação financeira, ao isolamento social e à marginalização do mercado de trabalho (Gallie e Paugam, 2000a), mas igualmente aos seus efeitos de mitigação dos direitos de cidadania económica das mulheres, de reforço das desigualdades intra-familiares e de redução da operatividade das redes sociais de apoio. ${ }^{18}$

\section{Considerações finais}

Parti da hipótese de que os mediadores de compensação - agindo isoladamente ou em articulação, temporariamente ou de forma mais prolongada poderiam conferir aos desempregados recursos e protecções diferenciadas e, nessa medida, suscitar experiências do desemprego mais ou menos integradas e vividas de forma mais autónoma ou dependente. Analisados os três elementos que compõe os mediadores de compensação, o que se verifica é que é o Estado social, mesmo se subprotector, quem se assume como elemento central na economia das protecções dos desempregados, aparecendo as redes sociais e as actividades de substituição como protecções complementares e, muitas vezes, precárias.

A relação entre Estado social e redes sociais, designadamente a família, aparece como sendo de complementaridade enquanto perduram as protecções garantidas pelo primeiro e de substitutibilidade findos os períodos de concessão. Esta relação de substitutibilidade torna-se tanto mais problemática quanto se vão acentuando as dificuldades que enfrentam as famílias para assegurar protecção aos seus membros, mais difíceis as reentradas no mercado de trabalho e mais agudas as situações de dependência.

Nas suas relações com as actividades de substituição, as protecções estatais assumem novamente um papel preponderante. $\mathrm{O}$ trabalho não declarado aparece como um risco e como pouco vantajoso, na medida em que pode

\footnotetext{
${ }^{18}$ Significa isto que, apesar de poder representar uma maior disponibilidade por parte daquelas que são, por excelência, quem assegura o funcionamento das redes sociais, o desemprego poderá enfraquecer as condições materiais para o seu funcionamento.
} 
implicar sanções e impede que se continue a trabalhar na sua carreira contributiva. O trabalho informal, por sua vez, embora fundamental para contrariar os efeitos desestabilizadores e estigmatizantes do desemprego, porque não remunerado, assume um carácter meramente e precariamente complementar.

Os factores de vulnerabilidade, extrinsecos como intrínsecos, desempenham, por seu lado, um importante papel enquanto redutores de oportunidades, pelo que, e isso só foi possível de verificar nas projecções relativamente à reentrada no mercado de trabalho, as esperanças de vir a encontrar um emprego com características similares à experiência anterior são extremamente reduzidas. Essenciais que foram no processo de modernização português, estes trabalhadores parecem agora obsoletos. Os discursos sobre a autonomia, sobre a independência, sobre a responsabilidade de cada um pela sua própria vida não poderiam ser aqui mais mistificadores, na medida em que os riscos sociais que enfrenta este grupo particular não poderiam ser mais reais.

É do Estado que se espera protecção. Uma protecção legítima, de resto, tendo em conta a carreira contributiva dos desempregados e as razões subjacentes à sua retirada do mercado de trabalho. Reclamar por mais protecção equivale a uma tomada de consciência, da pior forma possível talvez, do risco que representa o desemprego, particularmente o desemprego de meia-idade. É na medida em que o Estado social aparece como principal garante de segurança e estabilidade perante a ruptura involuntária com um percurso profissional onde estabilidade e segurança pareciam garantidas que o desemprego de meia-idade poderá definir-se como um acontecimento que compromete a capacidade dos indivíduos para assegurar a sua autonomia e que amplifica a função social do Estado, ou seja, o seu papel de redutor dos riscos sociais.

O encerramento das Cerâmicas Estaco representou para os indivíduos um momento de ruptura na estrutura sequencial do seu curso de vida que, tornando manifesta a força dos factores de vulnerabilidade, veio alterar drasticamente a sua relação ao emprego e que, tornando manifesta a fragilidade dos mediadores de compensação, veio conferir ao Estado social uma centralidade até aí inédita.

\section{Referências bibliográficas}

Araújo, Pedro (2006), E agora? Experiências do desemprego, factores de vulnerabilidade e mediadores de compensação. Coimbra: Faculdade de Economia da Universidade de Coimbra (dissertação de Mestrado em Sociologia).

Capucha, Luís Manuel Antunes (2000), "Territórios da pobreza, onde é preciso voltar", Sociedade e Território, 30, 8-15. 
Castel, Robert (2003), L'Insécurité Sociale. Qu'est-ce qu'être protégé?. Paris: Seuil.

Centeno, Luís (2003), "Exclusão social e desenvolvimento: como o novo mercado de trabalho pode ser um gerador de exclusão", Sociedade e Trabalho, 14/15, 33-46.

Centeno, Luís et al. (2001), "Os Trabalhadores de Meia Idade Face às Reestruturações e Políticas de Gestão de Recursos Humanos”, Estudos e Análises, 30, Observatório do Emprego e Formação Profissional.

Comissão Europeia (2004), Undeclared Work in an Enlarged Union. An Analysis of Undeclared Work: An In-Depth Study of Specific Items - Final Report. Brussels: Directorate-General for Employment and Social Affairs.

Conselho da Cidade (2004), "Dossier Estatístico: Coimbra, a cidade e o concelho", Apresentado no Colóquio A Crise da Indústria Coimbrã e os Efeitos do Desemprego, Coimbra, Conselho da Cidade, Núcleo Economia e Sociedade, 27 de Novembro 2004.

Demazière, Didier (1995), La Sociologie du Chômage. Paris: La Découverte.

Demazière, Didier; Dubar, Claude (1997), Analyser les entretiens biographiques. L'exemple des récits d'insertion. Paris: Nathan.

Gallie, Duncan; Paugam, Serge (orgs.) (2000a), Welfare Regimes and the Experience of Unemployment in Europe. Oxford: Oxford UP.

Gallie, Duncan; Paugam, Serge (2000b), "The Experience of Unemployment in Europe: The Debate", in Duncan Gallie; Serge Paugam (orgs.), Welfare Regimes and the Experience of Unemployment in Europe. Oxford: Oxford UP, 1-22.

Gallie, Duncan; Paugam, Serge (2000c), "The Social Regulation of Unemployment", in Duncan Gallie; Serge Paugam (orgs.), Welfare Regimes and the Experience of Unemployment in Europe. Oxford: Oxford UP, 351-374.

Hespanha, Pedro (1994), Com os pés na terra. Práticas fundiárias da população rural portuguesa. Porto: Afrontamento.

Hespanha, Pedro (2005), "The Activation Trend in the Portuguese Social Policy. An Open Process?”, Oficinas do CES, 225.

Hespanha, Pedro; Portugal, Sílvia (2002), A transformação da família e a regressão da Sociedade-Providência. Porto: Ministério das Cidades, Ordenamento do Território e Ambiente, Comissão de Coordenação da Região Norte.

Kovács, Ilona (2005), "Formas flexíveis de emprego em Portugal: riscos e oportunidades", Sociedade e Trabalho, 23/24, 47-66.

Lazarsfeld, Paul et al. (1981), Les chômeurs de Marienthal. Paris: Les Éditions de Minuit [1932].

Linhart, Danièle et al. (2003), Perte d'emploi, perte de soi. Paris: Éditions Érès.

Loison, Laurence (2000), "Mecanismos compensatórios do desemprego em Portugal: Família e redes sociais", Actas do IV Congresso Português de Sociologia, Sociedade Portuguesa: Passados recentes, futuros próximos. Universidade de Coimbra, 17-19 de Abril 2000. 
Martin, Claude (1995), "Os limites da protecção da família. Introdução a uma discussão sobre as novas solidariedade na relação Família-Estado”, Revista Crítica de Ciências Sociais, 42, 53-76.

Nunes, João Arriscado (1995), "Com mal ou bem, aos teus te atém: As solidariedades primárias e os limites da Sociedade-Providência”, Revista Crítica de Ciências Sociais, 42, 5-25.

Piselli, Fortunata (1995), "Sociedade-Providência na esfera económica”, Revista Crítica de Ciências Sociais, 42, 105-123.

Portugal, Sílvia (2001), “Os trajectos da globalização das políticas sociais. Da retórica global às práticas locais no Ano Internacional da Família”, in Pedro Hespanha e Graça Carapinheiro (orgs.) (2001), Risco social e incerteza: Pode o Estado social recuar mais?. Porto: Afrontamento, 301-336.

Portugal, Sílvia (2006), Novas famílias, modos antigos. As redes sociais na produção de bem-estar. Coimbra: Faculdade de Economia da Universidade de Coimbra (dissertação de Doutoramento).

Reis, José (1985), "Modos de industrialização, força de trabalho e pequena agricultura”, Revista Crítica de Ciências Sociais, 15/16/17, 225-260.

Reis, José (1992), Os espaços da indústria. A regulação económica e o desenvolvimento local em Portugal. Porto: Afrontamento.

Reis, José (1993), "Portugal: A heterogeneidade de uma economia semiperiférica", in B. S. Santos (org.), Portugal: Um retrato singular. Porto: Afrontamento, 133-161.

Rémillon, Delphine (2006), "L'épreuve de la recherche d'emploi vue par les chômeurs âgés”, Centre d'Étude de l'Emploi, Document de Travail, 61.

Rosa, Maria Teresa Serôdio et al. (2001), O desemprego numa zona crítica de Portugal. O caso de Azambuja: Realidades e perspectivas de transformação. Lisboa: Fundação Calouste Gulbenkian, Fundação para a Ciência e Tecnologia.

Santos, Boaventura de Sousa (1993), "O Estado, as relações e o bem-estar na semiperiferia: o caso português”, in B. S. Santos (org.), Portugal: Um retrato singular. Porto: Afrontamento, 15-56.

Santos, Boaventura de Sousa (2001), “A nova questão social”, in B. S. Santos, A cor do tempo quando foge. Crónicas 1985-2000. Porto: Afrontamento, 151-152.

Schnapper, Dominique (1994), L'épreuve du chômage. Paris: Gallimard [1981].

Vandermeer, Jeff (2006), A transformação de Martin Lake E Outras histórias. Lisboa: Livros de Areia.

Vasconcelos, Pedro (2005), "Redes sociais de apoio", in Karin Wall (org.), Famílias em Portugal: Percursos, interacções, redes sociais. Lisboa: Imprensa de Ciências Sociais, 599-631.

Wall, Karin (org.) (2005), Famílias em Portugal: Percursos, interacções, redes sociais. Lisboa: Imprensa de Ciências Sociais. 